therefore give out some light, but it is so feeble as to appear black by contrast with the very much brighter rays coming direct from the original source.

This great law may be summed up as follows: Gases and vapours, when relatively cool, absorb those rays which they themselves emit when incandescent; the absorption is continuous or discontinuous (or selective) as the radiation is continuous or discontinuous (or selective).

I have referred to this matter at some length because in our light sources, in the sun, and in many of the stars we have light from a more highly heated centre passing through an envelope of cooler vapours, and on this account absorption phenomena are produced.

Our knowledge of the chemistry of the sun and stars is founded upon the exact coincidence of the bright lines understand the exponential theorem, it is absurd to think that even average schoolboys who have been six years at mathematics can understand how logarithms are calculated. But if a schoolboy has been told what a logarithm means, and if he can extract a square root by the ordinary arithmetical method, and especially if he has had a sensible teacher and been allowed to use tables of logarithms, I think that he will have no difficulty in understanding the following method, and will rather enjoy working at it a little.

Let him find $10^{I / 2}, 10^{1 / 4}, 10^{I / 8}, 10^{1 / x}, 10^{I / 32}$, by repeatedly extracting square roots, getting out his answers to five significant figures, say. Let him now by multiplication calculate $103 / 3^{2}, 105 / 32$, \&c., right up to $10^{1}$. He thus has a table of which I give the beginning and end.

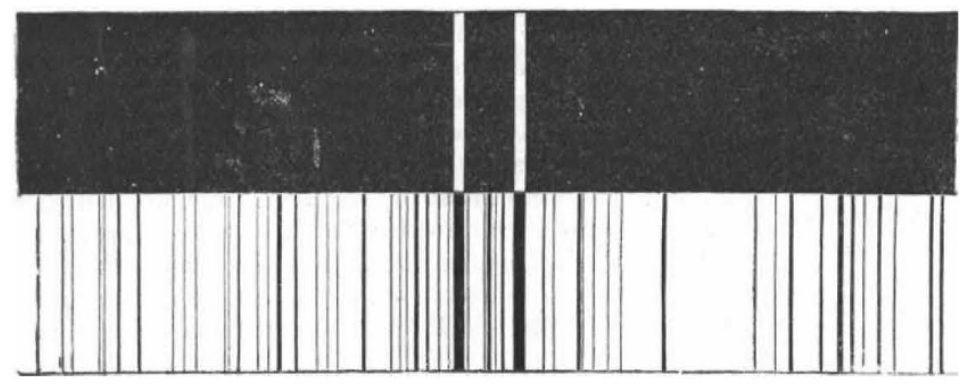

F1G. 12. - The coincidence of the bright double orange lines of sodium vapour with the

\begin{tabular}{c|c}
\hline Number. & Logarithm. \\
\hline I.0000 & 0.00000 \\
1.0746 & 0.03125 \\
$1 \cdot 1548$ & 0.06250 \\
$1 \cdot 2409$ & 0.09375 \\
$1 \cdot 3336$ & 0.12500 \\
. & $\cdot$ \\
$8 \cdot 0584$ &. \\
8.6596 & 0.90625 \\
$9 \cdot 3057$ & 0.09750 \\
10.0000 & 0.96875 \\
& 1.00000
\end{tabular}

seen in our laboratories with the dark lines noted in the spectra of those celestial bodies. The diagram shows the coincidence in the case of the double orange line of sodium vapour with dark lines in the spectrum of the sun.

Now if my reader has not hesitated to invest his or her sixpence in a prism, and has had the patience (no other quality is needed) to do what I have suggested, the way is open to read with intelligence most books involving spectrum analysis which he or she is likely to come across ; terms such as

$\begin{array}{ll}\text { Spectrum } & \text { Discontinuous (or selective) } \\ \text { Continuous spectrum } & \begin{array}{l}\text { spectrum } \\ \text { Fraunhofer lines }\end{array} \\ \text { Grating } & \text { Wave-length } \\ \text { Prism } & \text { Radiation } \\ \text { Spectroscope } & \text { Absorption } \\ \text { Slit } & \text { Series } \\ \text { Line spectra } & \\ \text { Fluted spectra } & \end{array}$

should now have acquired a definite meaning, and I trust the expressiveness of the terms will be acknowledged while they are accepted as part of the future mental stock-in-trade.

NORMAN LOCKYER.

\section{TO CALCULATE A TABLE OF LOGARITHMS.}

$\mathrm{H}^{\mathrm{A}}$ AVING been asked to give a short course of lectures to working men, which involved an account of logarithms and the slide-rule, I felt that, although not important, there would be some advantage in being able to show them how they could calculate a table of logarithms and a table of antilogarithms for themselves. Not that they need do so except as an interesting exercise, for I do not think it necessary that a man or boy must be able to make a tool before he is allowed to use it, but it would do them no harm to explain to them a simple method if I could invent one.

Of course on the usual assumption that one must first NO. I 530 , voL. 59]
If he plots these values on squared paper he gets a curve which enables him to find the logarithm of any number.

If he wants answers right to four significant figures, it is well to draw only a small part of the curve on one sheet of squared paper. Thus plotting the first three points so that the curve joining them (using a slightly bent straight-edge) passes diagonally through a small sheet of squared paper, one of my students has found answers which are sufficiently correct to impress a student with the value of the method. I give here seven values taken at random from the curves of the early and the late parts of the table. This was the first time that he had tried the method, and the small errors in the fourth significant figures are not likely to occur if a man has more practice.

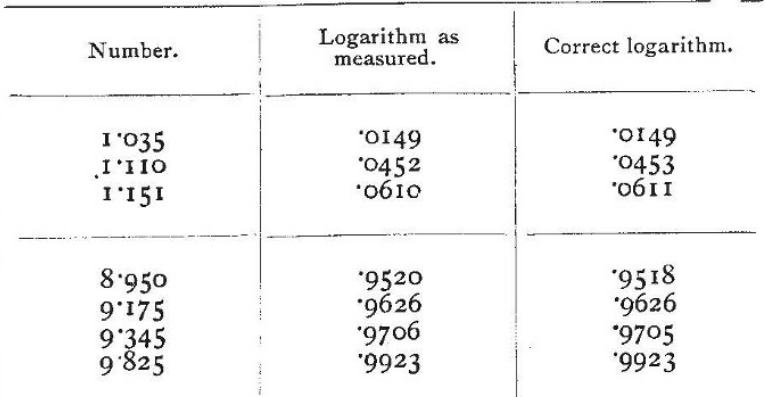

Even with the very cheapest squared paper we can construct tables of logarithms and antilogarithms which will be quite accurate to three significant figures, and by taking twice the trouble and using $10^{1 / 64}$ we may get $a$ table accurate to four significant figures, even with very cheap paper. Also it is to be noticed that by using $10^{1 / 128}$ and higher roots, we can find the logarithm of any particular number with any amount of accuracy desired.

Royal College of Science, February 16.
JOHN PERRY. 